\title{
Selection of HMG-coenzyme A reductase inhibitors using multiattribute scoring tool
}

\author{
Azuana Ramli ${ }^{*}$, Syed Mohamed Aljunid ${ }^{1}$, Saperi Sulong ${ }^{2}$, Faridah Aryani Mohd Yusof ${ }^{3}$ \\ From 6th Postgraduate Forum on Health Systems and Policies \\ Melaka, Malaysia. 21-22 May 2012
}

\section{Background}

Hypercholesterolaemia is a major risk factor for cardiovascular diseases. Treatment with HMG coenzyme A reductase inhibitors (statins) had been proven to reduce the risk. Due to high prevalence of hypercholesterolaemia, statins consumption is high. Statins available in Malaysia include atorvastatin, lovastatin, pravastatin, rosuvastatin, simvastatin and fluvastatin. All except one (fluvastatin) have piled up the MOH Drug Formulary (DF); hence the need to review the statins list. Multiattribute scoring tool (MAST) which takes into consideration all variables for rational decision making could help decision makers in reviewing the list. In this study, the six available statins were evaluated and scored.

\section{Materials and methods}

Published literatures were studied and five sessions of expert group discussions were conducted to build the MAST. The attributes (and factors) identified for analysis were efficacy (clinical efficacy, clinical end points), safety (drug interactions, hazardous side-effects, documentation), drug applicability (drug strength/formulation, indications, dose frequency, side-effects, food interactions, dose adjustments) and costs. The average weights assigned by group members for efficacy, safety, drug applicability and costs were $32.6 \%, 26.2 \%, 24.1 \%$ and $17.1 \%$ respectively. Utility values of attributes were scored based on published evidences or/and agreements during group discussions. Attribute scores were summed to provide total utility score for each statin.

\section{Results}

Atorvastatin scored the highest total utility score (TUS) of 77.88 , followed by simvastatin (75.05). Atorvastatin and simvastatin scored consistently high even before acquisition costs were included. Low score on side effects for atorvastatin were compensated by higher scores on clinical end points resulting in higher TUS for atorvastatin. Pravastatin, lovastatin and rosuvastatin received TUS of $71.95,71.45$ and 63.74 respectively. Fluvastatin had the lowest score of 59.83 .

\section{Conclusion}

The multiattribute utility scoring tool successfully systematizes decision variables to aid selection of statins for the formulary. Based on total utility scores calculated using the designed MAST, atorvastatin and simvastatin should be considered as first-lines in the treatment of hypercholesterolaemia.

\section{Author details \\ 'United Nations University-International Institute for Global Health, Universiti Kebangsaan Malaysia Medical Centre, Jalan Yaacob Latiff, 56000 Kuala Lumpur, Malaysia. ${ }^{2}$ Department of Health Information, Universiti Kebangsaan Malaysia Medical Centre, Jalan Yaacob Latiff, 56000 Kuala Lumpur, Malaysia. ${ }^{3}$ Pharmaceutical Services Division, Ministry of Health, 46350 Petaling Jaya, Malaysia.}

Published: 27 November 2012

doi:10.1186/1471-2458-12-S2-A21

Cite this article as: Ramli et al:: Selection of HMG-coenzyme A reductase inhibitors using multiattribute scoring tool. BMC Public Health 2012 12(Suppl 2):A21.

\footnotetext{
'United Nations University-International Institute for Global Health, Universiti Kebangsaan Malaysia Medical Centre, Jalan Yaacob Latiff, 56000 Kuala Lumpur, Malaysia

Full list of author information is available at the end of the article
}

(c) 2012 Ramli et al; licensee BioMed Central Ltd. This is an Open Access article distributed under the terms of the Creative Commons 